Revista de Literatura, História e Memória

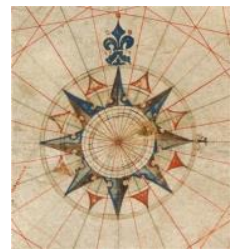

Seção: Pesquisa em Letras no contexto Latino-americano e Literatura, Ensino e Cultura

ISSN 1983-1498

VOL. 17 - No 29 - 2021

U N I O E S T E / CA S C A V E L - p. 64-77

\title{
TRAVESSIAS ENTRE A LITERARUTA E A HISTÓRIA DA REGIÃO AMAZÔNICA: UMA ANÁLISE DO CONTO "O DONATIVO DO CAPITÃO SILVESTRE" DE INGLÊS DE SOUSA
}

\author{
Crosses between literarute and the history of the \\ amazonian region: an analysis of the tale "The donation of \\ captain silvestre" by Inglês de Sousa
}

\author{
Karen Dos Santos Correia ${ }^{1}$ \\ Analaura Corradi ${ }^{2}$ \\ Douglas Junio Fernandes Assumpção ${ }^{3}$
}

RESUMO: Este artigo objetiva analisar a relação existente entre a literatura e a história amazônica no conto "O Donativo do Capitão Silvestre" de Inglês de Sousa. O cenário, os atores sociais e as relações homem-sociedade-natureza da região amazônica são representados nesta ficção inserida no livro Contos Amazônicos (1893). Nele, Inglês de Sousa aponta a confluência entre a literatura e a história do estado do Pará da segunda metade do século XIX e apresenta uma obra substanciada entre a ficcionalidade literária e a história do povo amazônida, destacando fatos e personalidades que fizeram parte da história do Pará. O processo metodológico se deu baseado na metodologia interpretativa, de modo a realizar uma revisão da literatura dos teóricos selecionados para a construção deste trabalho, tais como Alfredo Bosi (1990), Nicolau Sevcenko (1999) e Antônio Cândido (1957). Concluiu-se que o autor observou figuras típicas, costumes e fatos históricos e sociais da região amazônica, evidenciando as relações conflitantes entre tradição e modernidade, bem como os aspectos rurais e urbanos, e a ciência e os saberes populares. As crises políticas e o embate entre o homem e a sua região também fizeram parte dos apontamentos feitos na análise.

PALAVRAS-CHAVE: Literatura; História; Inglês de Sousa; O Donativo do Capitão Silvestre.

ABSTRACT: This article aims to analyze the relationship between literature and Amazonian history in the short story "The Donation from Captain Silvestre" by Inglês de Sousa. The scenario, the social actors and the man-society-nature relations of the Amazon region are represented in this fiction inserted in the book Contos Amazónico (1893). In it, Inglês de Sousa points out the confluence between literature and the history of the state of Pará in the second half of the 19th century and presents a substantiated work between literary fictionality and the history of the Amazonian people, highlighting facts and personalities that were part of the history of the Pará. The methodological process was based on the interpretative methodology, in order to carry out a review of the literature of the theorists selected for the construction of this work, such as Alfredo Bosi (1990), Nicolau Sevcenko (1999) and Antônio Cândido (1957). It was concluded that the author observed typical figures, customs and historical and social facts of the Amazon region, showing the conflicting relationships between tradition and modernity, as well as rural and urban aspects, and science and popular

\footnotetext{
${ }^{1}$ Doutoranda pelo Programa de Pós-Graduação em Comunicação, Linguagens e Cultura da Universidade da Amazônia (Unama). Relações Públicas na Universidade Federal do Oeste do Pará (Ufopa). Professora em cursos de graduação e pós-graduação nas áreas de Letras, Comunicação e Educação.

2 Professora titular na Universidade da Amazônia - UNAMA, Belém, Pará Brasil, nos cursos de Comunicação Social (Publicidade e Jornalismo) e do Programa de Pós-Graduação em Comunicação, Linguagens e Cultura.

${ }^{3}$ Professor da Escola Superior Madre Celeste (ESMAC) nos cursos de Bacharelado em Administração, Ciências Contábeis e Licenciatura em Letras. É Vice-Líder do Grupo de Pesquisa (GP) Estudos de Capital Social e Cultural no contexto da mídia contemporânea (UNAMA/CNPq). membro do GP Journalisme à 1?heure du numérique - JAND (Université Lumiré Lyon 2 / Lyon - França) e GP ECCOS - Estudos sobre Comunicação, Consumo e Sociedade (UFPR/CNPq).
} 
knowledge. Political crises and the clash between man and his region were also part of the notes made in the analysis.

KEYWORDS: Literature; History; Sousa's English; Captain Silvestre's Donation.

\section{INTRODUÇÃO}

Santo patriotismo popular, quantos heroísmos humildes e obscuros tens produzido nas épocas decisivas da nossa história! Alma generosa do povo brasileiro, quão mal apreciada és pelos eternos faladores da Câmara dos Deputados!

(Inglês de Sousa, 2005, p. 79).

O conto "O Donativo do Capitão Silvestre" de Inglês de Sousa (2005) historiciza, ficcionalmente, um patriotismo exacerbado do povo amazônico, mas pouco apreciado pelas autoridades políticas da época. Vê-se um conflito político e social marcado por interesses patrióticos da população e por manipulações e explorações das autoridades.

De modo prosaico, Inglês de Sousa escreveu sobre fatos históricos e conflitos sociais, políticos e econômicos que marcaram a vida das pessoas na região amazônica, apresentando como principal característica de sua obra o enfoque no contexto amazônico. O patriotismo, a política, o social e a condição reduzida dos seres humanos ficaram marcados "nos entroncamentos do romantismo e do realismo-naturalismo" (TUPIASSU, 2005, p. 17), enfatizando a criticidade às instituições sociais baseado em uma abordagem naturalista.

Contava histórias dos personagens, da natureza, da vida na Amazônia e a configuração de um homem racional. Ele fez dos problemas humanos da Amazônia a preocupação central de sua obra Contos Amazônicos (2005), retratando uma parte da história da Amazônia do ano de 1862, época a qual trata a obra. Nela aparecem os modismos típicos da região.

Inglês de Sousa estabelece sua obra literária, puxando também meadas românticas, associadas de preferência, ao pensamento do habitante inculto das brenhas e dos recônditos rios da Amazônia. Este habitante não assistido pelo Estado, pelo poder institucionalizado, pertence à camada pobre da sociedade; é o ser encurralado nas teias da solidão e de necessidades pungentes. (TUPIASSU, 2005, p. 19).

Percebe-se que a obra narra histórias sobre as expressões do povo amazônico e as más condições sociais e econômicas. Uma crítica à política da época, lançando, portanto, a ideia de racionalidade à obra. Assim, por englobar aspectos históricos singulares da vida 
amazônica, têm-se elementos literários que traduzem, ficcionalmente, a história do Pará.

Tem-se, também, aspectos da história de Óbidos/PA, cidade natal do autor e município que referencia geograficamente o conto "O Donativo do Capitão Silvestre" que leva o leitor a descobrir imagens da vida amazônica, bem como suas paisagens.

Dessa forma, este artigo objetiva analisar a relação existente entre a literatura e a história amazônica no conto "O Donativo do Capitão Silvestre" de Inglês de Sousa. Para tanto, utilizou-se a metodologia interpretativa, realizando uma revisão da literatura baseada em teóricos selecionados para o foco deste trabalho, dentre eles estão: Alfredo Bosi (1990), Nicolau Sevcenko (1999) e Antônio Cândido (1957).

\section{INGLÊS DE SOUSA: ENTRE O DIREITO, A POLÍTICA E A PRODUÇÃO LITERÁRIA}

No dia 28 de dezembro de 1853, no município de Óbidos, estado do Pará, nasceu Herculano Marcos Inglês de Sousa, autor do conto "O Donativo do Capitão Silvestre" que compõe a obra Contos Amazônicos (2005). Filho de Marcos Antônio Rodrigues de Sousa e de Henriqueta Amália de Góis Brito Inglês, Inglês de Sousa, como ficou conhecido, pertenceu a uma das famílias mais tradicionais e abastadas do estado do Pará, o que lhe deu condições para morar em várias cidades do país e avançar nos estudos e na produção literária.

Em 1870, ingressou na Faculdade de Direito de Pernambuco e, durante este período, suas principais atividades se voltavam aos estudos jurídicos e políticos. Mas, em 1873, começou a publicar artigos e ensaios de crítica literária e filosófica no Jornal Lábaro de Recife/PE.

Porém, não permaneceu por muito tempo em Recife/PE, indo morar em outras cidades como Rio de Janeiro/RJ e São Paulo/SP - e nesta, formou-se pela Faculdade de Direito, em 1876. Ainda neste ano, publicou as obras O Cacaulista (1876) e História de um Pescador (1876), e no ano seguinte publicou O Coronel Sangrado (1877) - todos compondo a série Cenas da Vida do Amazonas. E em 1891, ainda neste ciclo narrativo publicou O Missionário (1888). Em toda essa série literária, Inglês de Sousa usou o pseudônimo Luís Dolzani.

O autor também atuou na política, conquistando cargos importantes que lhe trouxeram grande experiência, como em 1878, quando foi nomeado Secretário de Relações de São Paulo. De 1880 a 1881, foi deputado da Assembleia Legislativa Provincial de São Paulo, e de 1881 a 1882, foi Presidente da Província de Sergipe. E ainda em 1882, voltou a ser deputado da Assembleia Legislativa Provincial de São Paulo. Mas, em 1883, perdeu a nomeação à 
Assembleia Geral, o que lhe fez abandonar a carreira política e se dedicar às áreas jurídica e literária.

Assim, sua vida seguiu atuando tanto na advocacia quanto na literatura. Observa-se que ele foi uma referência na área da advocacia no país e, também, ficou conhecido como um grande escritor sobre a região amazônica. Em 1893, no Rio de Janeiro, publicou sua última obra Contos Amazônicos (1893).

Em 1896, tornou-se um dos membros fundadores da Academia Brasileira de Letras, onde redigiu o projeto de estatutos. Em 1908, se tornou presidente do Instituto da Ordem dos Advogados, presidindo o $2^{\circ}$ Congresso Jurídico Brasileiro. E em 1918, faleceu no dia 6 de setembro, no Rio de Janeiro/RJ.

Inglês de Sousa retratou em seus romances o cenário e o modo de vida da sociedade amazônica da segunda metade do século XIX. Em suas obras, preocupou-se em mostrar os costumes, os hábitos, a sociabilidade provinciana, os conflitos de terras, bem como os preconceitos raciais, a linguagem regional e as superstições e crendices populares. (NEGER, 2009).

Percebe-se que a sua prosa ficcional relata fatos históricos ocorridos no período de escritura desses romances, pois entre os anos de 1840 e 1880 houve o declínio do ciclo do cacau e a expansão do ciclo da borracha (1879-1912), o qual foi elementar para o crescimento econômico e social do Brasil, pois a demanda internacional pela borracha era cada vez mais crescente, provocando um aumento no desenvolvimento econômico, demográfico e social na região amazônica, fatos que foram historicizados ficcionalmente em sua obra.

Começaram então a surgir transformações nos sistemas de transportes fluviais, como a abertura do rio Amazonas à navegação internacional, a ampliação da imigração nordestina em busca de trabalho e qualidade de vida, e, com isso, o crescimento populacional das capitais de Belém/PA e Manaus/AM. Diante disso, baseado em fatores que construíram parte da história da vida amazônica Inglês de Sousa publicou seus romances da série Cenas da Vida do Amazonas.

Raquel Neger (2009) diz que:

Coadunando prosa ficcional com relatos históricos, o autor oferece um quadro fiel e marcadamente documental da cultura cacauieira amazônica de seu tempo. Foi precisamente por esquadrinharem o cotidiano, retratando os costumes e hábitos populares, que suas obras são consideradas preciosas fontes de informação, revelando registros de inestimável valia para uma leitura socioantropológica. (NEGER, 2009, p. 13). 
E ainda,

\begin{abstract}
Sousa destaca-se de seus contemporâneos regionalistas por trazer para a ficção brasileira a realidade ambiental e social da região amazônica, usando uma prosa objetiva e analítica, voltada para o exame dos fatos históricos. Inglês de Sousa retrata o processo de reeuropeização pelo qual o país passaria em meados do século XIX, assimilando os hábitos, costumes e padrões de comportamento anglo-franceses. (NEGER apud BOSI, 2009, p. $13)$.
\end{abstract}

Assim, pode-se dizer que Inglês de Sousa recebeu inspiração dos atores sociais que fizeram parte da história da Amazônia no período de grandes transformações sociais e econômicas, produzindo, portanto, uma literatura realista e, ao mesmo tempo, naturalista. Reproduziu o cotidiano das populações amazônicas, por meio de narrativas que relatam, ficcionalmente, a história do povo amazônico.

Porém, mesmo com uma inclinação voltada para a vida jurídica, na literatura, Inglês de Sousa conseguiu trabalhar em seus textos não só as imagens, os encantos, o fantástico e o maravilhoso da Amazônia, mas, também, o enfoque no próprio povo amazônico, muitas vezes tratado como vítima social e uma população esquecida pelos governantes da época.

Tais características fizeram de seus escritos obras elementares como contribuição literária na segunda metade do século XIX. Era um tempo que se fortalecia a liberdade de expressão, e a exploração da sensibilidade e subjetividade estava cada vez mais presente nas artes. Apropriando-se disso, Inglês de Sousa tratava em suas obras a vida e as personalidades de seus residentes, tornando-as “um documento social de grande valor" (LEITE, 2002, p. 39).

\title{
3 ANÁLISE DO CONTO “O DONATIVO DO CAPITÃO SILVESTRE”: ASPECTOS HISTÓRICOS E LITERÁRIOS
}

O conto gira em torno de um incidente ocorrido na Baía de Guanabara, no Rio de Janeiro/RJ, em que os ingleses ferem a "dignidade nacional, mandando aprisionar navios brasileiros em plena paz” (SOUSA, 2005, p. 85). "Era o ano de 1862 [...]” (SOUSA, 2005, p. 77) quando a notícia desse episódio chegara à Óbidos, pequena região amazônica do estado do Pará, provocando grande agitação na região.

Decorrem, então, desse acontecimento patrióticas listas de subscrição, que tinha por objetivo angariar recursos para ajudar o tesouro público como forma de sustentar uma possível luta armada contra a Inglaterra. E ao necessitar da ajuda de todos, principalmente dos mais abastados do município, o Capitão Silvestre - o obidense mais rico da época - foi 
convidado pelo coronel Gama e pelo Juiz Municipal a contribuir na lista de donativos, que também crescia com a ajuda da população que oferecia desde ovos, galinhas, cacaus secos, bananas até bacamartes, sendo esta "[...] uma moeda de ouro dos Estados Unidos que corria então com abundância no interior do Pará. Valia pouco, mais ou menos trinta e seis mil réis da nossa moeda" (SOUSA, 2005, p. 83).

$\mathrm{O}$ conto enseja um grande impacto ao abordar temas ligados à história do Brasil, à história do Pará e à denúncia do descaso do governo nacional com a região amazônica. "O Donativo do Capitão Silvestre" reflete claramente os ânimos da região no momento da eclosão da Questão Christie, fato histórico que se refere ao principal incidente diplomático ocorrido durante o Segundo Reinado com a Inglaterra, em que três oficiais da marinha inglesa, à paisana e completamente bêbados, promoveram um tumulto no bairro da Tijuca, no município do Rio de Janeiro/RJ, e foram detidos no distrito policial. William Christie, embaixador inglês que acabou por denominar o fato com seu próprio nome, transformou essa simples ocorrência policial em um sério conflito diplomático entre as duas nações.

O conto retrata ainda uma estreita relação entre o homem e o espaço na Amazônia e entre a história (Questão Christie) e o episódio particular narrado sobre o donativo do Capitão Silvestre que serviria para comprar armamento a ser usado na guerra contra a Inglaterra. Esse conto, segundo Amarílis Tupiassu (2005), está “[...] dentro dos padrões da estética realistanaturalista, todos dispostos de modo a revelar um contexto histórico que se critica em nome do saber positivo, da ciência, do progresso e da paz”. (TUPIASSU, 2005, p. 26).

A linguagem do conto é objetiva e bastante concisa, caracterizando-se por uma oralidade adequada, uma vez que reproduz uma experiência vivida pelo narrador, como mostra o $1^{\mathrm{o}}$ parágrafo do conto, narrado em $2^{\mathrm{a}}$ pessoa, "Quereis saber a história do donativo que fez o Capitão Silvestre para a guerra contra os senhores ingleses?" (SOUSA, 2005, p. 77).

O $2^{\circ}$ parágrafo, mostra o conto narrado em $1^{\text {a }}$ pessoa: "Posso vo-la contar, porque me achava em Óbidos nessa ocasião e fui testemunha ocular do fato" (SOUSA, 2005, p. 77), informando o local onde se passa a narrativa e a posição de autor e narrador que surge logo no início do conto, mostrando uma relação entre a literatura e a história no conto.

$\mathrm{O}$ início do $3^{\circ}$ parágrafo, narrado em $3^{\mathrm{a}}$ pessoa "Era no ano de 1862, e chegara no Pará o vapor de Manaus, trazendo notícia circunstanciada do conflito levantado pelo ministro inglês William Dougal Christie [...]" (SOUSA, 2005, p. 77), mostra o que narrador deseja contar, e mantém a voz em $3^{\text {a }}$ pessoa durante quase todo o conto, com exceção em que esse narrador aparece como personagem da narrativa e afirma ir ver e conversar com o 
Capitão Silvestre, sendo recebido por ele até a chegada do coronel Gama e do Juiz municipal - neste momento o narrador volta ao seu lugar de observador em $3^{\mathrm{a}}$ pessoa e testemunha a conversa entre o Capitão Silvestre e os dois mencionados. "Tendo-o visto chegar, fui vê-lo. Recebeu-me familiarmente, sem levantar-se do baú em que se assentara. Conversávamos alegremente sobre a colheita do ano, quando avisaram a visita do coronel Gama e do Juiz Municipal [...]”' (SOUSA, 2005, p. 84).

No parágrafo seguinte, o narrador faz uma descrição do sentimento do povo em relação à atitude de Willian Christie, sendo expressado, pelo narrador onisciente, um sentimento de indignação generalizada por parte do povo: “A atitude arrogante e violenta de Christie indignara o povo, despertando o pundonor nacional, agitando patrioticamente os ânimos." (SOUSA, 2005, p. 77) e do $5^{\circ}$ parágrafo “Correra uma faísca elétrica do Sul ao Norte do Império e a corda do sentimento de nacionalidade, adormecida desde as sangrentas lutas da nossa integração política, posteriores à independência, vibrou sonoramente no coração dos paraenses." (SOUSA, 2005, p. 77).

Neste mesmo trecho, percebe-se que o nacionalismo local é metaforizado na figura da faísca elétrica e da corda que vibra sonoramente no coração da população. Esta figura do fogo representado nos termos "faísca", "incêndio" (que representa o seu amplo grau de abrangência), "ardor" (que é o seu efeito sensível no corpo), "centelha” (representando a sua potencialidade de alastramento) é repetida diversas vezes no conto, e pode ser, simbolicamente, uma referência ao conflito histórico armado que se insurgia no momento, ou unicamente ao sentimento patriótico extremamente forte e intenso. Também na figura da corda vibrando sonoramente pode remeter à forte expressão nacionalista cada vez mais intensa entre o povo da região.

E ao tratar do amor à região amazônica, há no conto o termo "Os filhos $d a$ Amazônia", referindo-se que a região é retratada como a grande mãe de todo o povo, apelando-se para o sentimento familiar.

Tem-se, também, a intensa e até exagerada repetição dos termos "pundonor nacional", "agitando patrioticamente", "sentimento de nacionalidade”, "patriotismo dos brasileiros/paraenses", "dedicação/entusiasmo patriótico", "brios nacionais" e de termos semanticamente semelhantes, que aparecem dezoito vezes ao longo da curta narrativa e que denota o caráter altamente patriótico que se deseja ressaltar no episódio narrado.

No trecho "[...] fora lembrado o meio das subscrições populares para remediar a carência de recursos no tesouro público” (SOUSA, 2005, p. 77), encontrar-se a palavra subscrição, que nesse contexto, corresponde à lista feita com vistas a angariar recursos para 
determinado fim. Passa-se a narrar o problema do governo com a escassez de recursos no tesouro nacional e a necessidade de levantamento de recursos com fins bélicos entre a população, constituindo o motivo que levou o desenrolar do episódio narrado.

O conto retrata a vida popular amazônica da época, as atividades, práticas e elementos da cultura e a vida do povo paraense, que se manifestam também nos diversos termos regionais utilizados. "[...] até o produto de meia dúzia de ovos de galinha, trazidos por alguma tapuia, havia donativos de todos os valores, nada mais tocante do que ver a humilde fiandeira de algodão, o simples pescador de tartarugas, lançar mão do único recurso que tinha em casa..." (SOUSA, 2005, p. 78).

O sentimento de rivalidade que se alastrava e o conflito armado que se formava é evidenciado no conto pela utilização de termos relacionados aos conflitos bélicos "baioneta", “armamento”, “canhões negros e ameaçadores” etc. e pela incitação popular que, como descrito no conto, era realizada em todo o estado, porém o relato é feito especificamente com relação à cidade de Óbidos/PA. A população se encorajava mutuamente a participar tanto da lista de donativos quanto do eminente conflito contra os ingleses.

Além disso, subestimavam os ingleses, os comparavam aos animais, tornavam motivo de chacotas a aparência, os costumes, a cultura, a língua e o falar dos ingleses; e exaltavam a superioridade, a valentia e o heroísmo provenientes do patriotismo popular local - traduzidos pelos termos “animação”, "dedicação" e "entusiasmo patriótico”, que aparecem diversas vezes: "Santo patriotismo popular, quantos heroísmos humildes e obscuros tens produzido nas épocas decisivas da nossa história!” (SOUSA, 2005, p. 79); "Pois vocês, meu povo, estão com medo dos tais ingleses 'comes franges com batates?"” (SOUSA, 2005, p. 80); “A animação e o entusiasmo patriótico cresciam.” (SOUSA, 2005, p. 81); “Os ingleses atacavam a murros e 'goddemes', e o Permanente era só rasteiras e cabeçadas, e zás! trancafiou os 'beefs' no xilindró." (SOUSA, 2005, p. 81).

Outro termo muito utilizado é "bacamarte", o qual é explicado na própria narrativa como sendo uma moeda de ouro dos Estados Unidos que circulava com abundância no interior do Pará. Em toda a narrativa, a principal medida monetária que se observa é o "Bacamarte", utilizado também pelo Capitão Silvestre no final da narrativa, que doa "cem bacamartes". No entanto, esta palavra carrega sentidos bastante diferenciados, os quais podem ser aplicados para se compreender melhor o episódio narrado.

O termo "bacamarte" pode fazer referência a um determinado tipo de arma de fogo, o que aponta para a intenção de início de uma guerra contra o próprio governo, quando o Capitão Silvestre resolve doar “cem 'bacamartes' de ouro! [...] e quinhentos cartuchos 
embalado para guerrear esse governo que barateia os brios da Nação" (SOUSA, 2005, p. 87). Esse termo pode, também, ser utilizado para se referir a algo inútil, imprestável, um traste. Neste caso, este uso apontaria para o fato de que toda essa iniciativa de angariar recursos com o povo e de convencer o Capitão Silvestre a fazer um grande donativo era inútil, nada disso valeria coisa alguma. E é exatamente o que se pode concluir do final da narrativa.

O conto não deixa de ser uma crítica ao governo da época, como disse o próprio personagem principal, o Capitão Silvestre, "esse governo que barateia os brios da Nação" (SOUSA, 2005, p. 87), ou seja, um governo que só fazia baratear o orgulho e a dignidade da nação, visto que não tinha condições de participar de um conflito contra a Inglaterra por mais patriota e doador que o seu povo pudesse ser. É uma crítica à própria sociedade que se deixava seduzir por propostas inviáveis e aos magistrados civis e judiciários da cidade. $\mathrm{O}$ conto mostra que o Capitão Silvestre representa a mente sensata que percebe a inviabilidade do que estava sendo proposto.

Sylvia Perlingeiro Paixão, na Introdução de Contos Amazônicos, da edição de 2004, diz que a região amazônica é a própria autora da ficção, pois ela é capaz de se esconder por trás do autor de forma fascinada, impondo um naturalismo que narra sua própria existência. $\mathrm{O}$ "[...] o regionalismo de Inglês de Sousa, cujos contos procuram fixar o homem na paisagem amazônica, surpreendendo e apreendendo suas lutas e fraquezas em meio a um ambiente natural propício ao nascimento de deuses e demônios [...]" (PAIXÃO, 2004, p. 26).

Dessa forma, percebe-se que o próprio autor se baseou em diversos contextos regionais, sociais e históricos da região onde nasceu. A partir disso, percebe-se que o " $\mathrm{O}$ Donativo do Capitão Silvestre" se refere, explicitamente, ao momento em que Inglês de Sousa já havia nascido e participava, indiretamente, dos fatos ocorridos na época. $\mathrm{O}$ folclorista Vicente Salles ${ }^{4}$, afirmou na introdução da segunda edição de História de Um Pescador (1990) que Inglês de Sousa usou a figura de seu avô Silvestre José Rodrigues de Sousa para descrever o Capitão Silvestre. E ainda Amarílis Tupiassu:

Ecoam por essas composições muitas vozes das quais se expande um tom autobiográfico bem marcado. Essas marcações verídicas, quem as expressa é o próprio narrador, quando assinala uma nomeação que indica nomes e sobrenomes inscritos na biografia de Inglês de Sousa. Um caso está registrado em $O$ donativo do capitão Silvestre (Silvestre José Rodrigues de Sousa) seria o bisavô do escritor? (TUPIASSU, 2005, p. 26).

\footnotetext{
${ }^{4}$ Nasceu em Igarapé-Açu, no estado do Pará, em 1931. Foi um escritor e pesquisador brasileiro que concentrou seus estudos na literatura, na música e no folclore.
} 
Dessa forma, percebe-se que a história de Inglês de Sousa está, intimamente, ligada à ficcionalidade literária que produziu, relacionando história e literatura, pois é possível encontrar a sua experiência de vida em seus escritos e a realidade por meio dessa produção literária à medida em que essa experiência se torna constituída dos fatores sociais ${ }^{5}$.

A partir dos fatos históricos presentes no conto, tem-se as ideias de Sevcenko (1999), que defende a análise histórica da linguagem, considerando-a como "centro de toda a atividade humana". Ele a define como um instrumento que modela a maneira de perceber e compreender a realidade e não somente um produto estabelecido pelo jogo de relações dos homens com a realidade social. Assim, a história e a linguagem literária, juntas, podem servir para estudar a vivência humana, na medida em que entende que a ação do homem flui sobre a realidade a partir da palavra, isto é, por meio de seu aspecto semântico.

Dessa forma, a literatura, como produção discursiva, é importante para interpretar os fatos históricos da narrativa, afinal, apesar da literatura não reproduzir a realidade tal qual é, ela se expõe "à infiltração corrosiva da dúvida e da perplexidade. É por onde o desafiam também os inconformados e os socialmente mal-ajustados" (SEVCENKO, 1999, p. 20). O que está posto nesta posição, assumida pelo autor, é a compreensão de uma "independência estreita" entre textos literários e estrutura social.

O ponto de interseção entre história, literatura e sociedade para Sevcenko (1999), está na figura do escritor. $\mathrm{O}$ autor defende que é muito importante verificar a situação em que o escritor está, ou seja, fazer um estudo analisando o meio social e o período em que o escritor se encontra. Neste caso, temos a seguinte passagem no conto "Posso vo-la contar, porque me achava em Óbidos nessa ocasião e fui testemunha ocular do fato, Era no ano de 1862, e chegara do Pará o vapor Manaus, trazendo notícia circunstaciada do conflito levantado pelo ministro inglês William Dougal Christie” (SOUSA, 2005, p. 77).

Este trecho se refere à Questão Christie, um momento da história brasileira em que Inglês de Sousa tinha apenas 9 anos, no entanto, como já foi dito se refere à vivência de seu avô. A Questão Christie corresponde ao momento em que o Brasil e a Inglaterra rompem sua relação diplomática devido um conflito ocorrido entre oficiais do Brasil e da Inglaterra, onde os oficiais brasileiros aprisionaram os britânicos por estarem embriagados e de fardas. E logo após este episódio houve um naufrágio de um navio britânico no sul do país, e Willian Christie, embaixador inglês, acusa os oficiais brasileiros de assassinarem os oficiais britânicos e depois furtarem os objetos que tinham no navio.

\footnotetext{
${ }^{5}$ Termo foi defendido por Émile Durkheim (1858-1917) como aqueles fatores que correspondem às maneiras de ser, fazer, pensar, agir e sentir - aspectos que podem ser compartilhados de forma coletiva em uma sociedade.
} 
Além disso, o conto faz alusão, também, ao vapor de Manaus, se referindo ao navio que foi entregar esta notícia ao município de Óbidos/PA, como diz no conto: "Grupos formavam-se nas esquinas, às portas das lojas, em conversações agitadas e inquietas" (SOUSA, 2005, p. 79). Assim, elementos mostram o quanto o meio social e a história contribuíram para a construção da obra literária.

As transformações dos fatos históricos em "fatos literários", afirma Sevcenko (1999), ocorre na composição da forma das obras e se realiza por contraversões sucessivas, que reflete e amplifica as tensões que os autores estavam submetidos. Esta "composição da forma" é gerada e se sustenta nos modelos de linguagem. As escolhas de linguagem resultam "como não poderia de ser" de opções históricas. Dentro disso, percebe-se como a literatura se transforma em um instrumento privilegiado de difusão de convicções. Para ele, elas estão na própria textura de sua linguagem e insiste na constatação de que os textos de seus autores apresentam um retrato do presente, englobando registros e anotações em que o tempo possa captar o real.

Assim, a partir dos estudos de Sevcenko (1999), constata-se que os textos literários são fontes excepcionais no cruzamento entre a história e a literatura, pois permite ver que a produção literária é um processo homólogo ao histórico, na medida em que defronta ou negao, porém, referindo-se sempre a ele. Nem reflexo, nem determinação, nem autonomia; o que se tem entre o campo da história e o campo da literatura é um intercâmbio tenso de confrontação, deduz, pois, que "a criação literária revela todo o seu potencial como documento" (SEVCENKO, 1999, p. 246).

Contudo, como o escritor "representa a história?", Sevcenko (1999) diz que a "história apresenta-se então ao escritor como o advento de uma opção necessária entre várias morais de linguagem: obriga-o a significar a literatura segundo possíveis que ele não domina". Aqui, expressa-se para ele o trabalho do escritor de materializar na linguagem as tensões sociais de seu tempo.

Antônio Candido (1957) comenta o seu método, histórico e estético, ao mesmo tempo, e mostra que certos elementos da formação nacional (dado histórico-social) levam o escritor a escolher e tratar de maneira determinada alguns temas literários (dados estéticos). Então, a tarefa do crítico é expor este movimento entre o geral (realidade histórica) e o particular (forma estética). O produto artístico é o equilíbrio deste movimento, a "tensão dos opostos".

É evidente que a literatura não é um documento histórico e ao ser escrito na intencionalidade de sê-lo, mesmo que seja através de significações ocultas, não tem nenhuma obrigação de representar o real, mesmo que parta dele ou para além dele. Todavia, enquanto 
uma certa historiografia está preocupada em bem representar este real, sempre a partir de uma farta comprovação, de preferência documental, a boa literatura está empenhada na construção do seu efeito artístico, através de imagens, mesmo baseada em fatos históricos.

Tanto o literato quanto o historiador são narradores, porém, verifica-se que a experiência histórica se plasma diferentemente em cada uma das narrativas. Entende-se que a questão não está em dizer que uma ou outra explana melhor esta experiência, mas saber como melhor construí-la.

No conto temos como exemplo, o próprio Capitão Silvestre, o obidense mais rico do município e que deveria ser uma das pessoas a contribuir com o donativo mais alto para ajudar na guerra contra os ingleses, pois só com o armamento do país não seria possível vencer. Assim, esses elementos que foram reais na história servem para serem utilizados na obra com o objetivo de registrar o que o meio e o tempo proporcionaram à construção da narrativa.

Exemplificando com um trecho no conto, temos: "Entretanto, as circunstâncias eram críticas. $O$ inglês ameaçava a cidade do Rio de Janeiro, que não está preparada para a defesa, e o nosso país, como todos nós sabemos, não pode lutar de frente com as hostes da soberana dos mares" (SOUSA, 2005, p. 85), referindo-se aos navios ingleses, que tinham muitas armas e canhões.

A diferença entre literatura e história está no fato da história sempre representar o real a partir de dados e comprovações que a própria sociedade e o tempo proporcionam. Já a literatura não tem essa intencionalidade, não está preocupada em registrar dados e se tornar um documento histórico, pois ela é uma escritura autônoma, mas social. Assim, fica claro que Inglês de Sousa utiliza bastante a ficção em sua obra.

Porém, fica claro que o autor se preocupa em colocar em suas obras os costumes, os hábitos, as tradições, a política e a economia da Amazônia, bem como seus próprios atores sociais. Sempre destaca o lugar, ora no meio rural de Óbidos/PA, ora no meio urbano deste município.

O patriotismo está constantemente mencionado no conto, afinal, ele aborda uma luta contra os ingleses e o anseio do povo brasileiro em defender sua nação. Dessa forma, dotado de sentimento de pertencimento à terra, na narrativa o povo se uniu e tentou se preparar para lutar contra seu inimigo. Dentro disso, esse patriotismo pode se manifestar na guerra, um sentimento que já vem desde a Cabanagem, movimento histórico mencionado brevemente nesta narrativa, porém, mais aprofundado em outros contos amazônicos de Inglês de Sousa. 


\section{CONSIDERAÇÕES FINAIS}

Percebeu-se que Inglês de Sousa se preocupou com a observação rigorosa de figuras típicas, costumes e fatos históricos e sociais para escrever o conto "O Donativo do Capitão Silvestre". Sua narrativa compõe um vasto painel da região amazônica, em que se destacam os conflitos entre tradição e modernidade, rural e urbana, ciência e saberes populares, crises políticas e sociais, e o embate entre o homem e a sua região.

São temáticas com marcadores precisos da história, não como um documento histórico propriamente dito, pois a literatura não usa fatos históricos como a história - comprova fatos por meio de documentos precisos, mas do modo como essas informações são ricamente tratados no campo da literatura pelo autor. Dessa forma, foi considerada a abordagem que Nicolau Sevcenko (1999) utilizou nos seus estudos, indicando a linguagem literária como um elemento essencial para entender e conhecer a história.

Afinal, "Toda a história é, nos contos de Inglês de Sousa, um resgate de uma memória nacional através da ficção." (COUTO, 2014, p. 8), pois ele escreveu prosaicamente, com aspectos literários, as cenas que fizeram parte da vida dos amazônidas neste período histórico, coadunando história e ficção.

\section{REFERÊNCIAS}

BOSI, Alfredo. História Concisa da Literatura Brasileira. São Paulo: Cultrix, 1990.

CANDIDO, Antônio. Formação da literatura brasileira. São Paulo: Ouro Sobre Azul, 1957.

COUTO, Jéssica Teixeira. Inglês de Sousa na obra Contos Amazônicos: O homem na luta com o mundo selvagem. XIV Congresso Internacional de Humanidades Dimensão temporal e espacial da linguagem e da cultura nos contextos latinoamericanos. 2014. Disponível em: https://2014.revistaintercambio.net.br/24h/pessoa/temp/anexo/1003/1306/2117.pdf. Acessado em: 14/05/2020.

LEITE, Marcus Vinícius Cavalcante. Cenas da vida amazônica: ensaio sobre a narrativa de Inglês de Sousa. Belém/PA: Unama, 2002.

NEGER, Raquel Ripari. Inglês de Sousa e a belle époque amazõnica: um estudo sobre a 'civilidade' e a 'matutice' na Óbidos do século XIX. Revista Travessias, v. 3, n. 1 (2009). Disponível em: $\quad \underline{\text { http://e-revista.unioeste.br/index.php/travessias/article/view/3267/2580. }}$. Acessado em: 12/12/2020.

PAIXÃO, Sylvia Perlingeiro. Indrodução. In: SOUSA, Inglês de. Contos Amazônicos. Rio de Janeiro/RJ: Martins Fontes, 2004. 
SEVCENKO, Nicolau. Literatura como missão: tensões sociais e criação cultural na Primeira República. São Paulo: Brasiliense, 1999.

SOUSA, Inglês de. Contos amazônicos. Belém/PA: EDUFPA, 2005.

TUPIASSU, Amarílis. Inglês de Sousa e a consciência de ser amazônico. (Prefácio). In: SOUSA, Inglês de. Contos Amazônicos. Belém/PA: EDUFPA, 2005.

Recebido: $14 / 05 / 2020$

Aprovado: 20/01/2021 